\title{
Immunoglobulin M Autoantibody to Vimentin
}

\section{Intermediate Filaments}

\author{
J. L. Senecal, N. F. Rothfield, and J. M. Oliver, Division of Rheumatic \\ Diseases, Department of Medicine, Department of Physiology, University of \\ Connecticut Health Center, Farmington, Connecticut 06032
}

A B S T R A C T Serum from a patient with the CREST Syndrome and systemic lupus erythematosus contained an IgM antibody that reacted at dilutions up to $1: 800$ with a fibrous cytoplasmic network in several epithelioid and fibroblastic cell lines. The antibody was shown by immunofluorescence microscopy to label a specific subset of cytoskeletal polymers, the intermediate filaments. The reactive antigen from this biochemically heterogeneous group of filaments was established as the $58,000-\mathrm{mol}$ wt protein, vimentin: $(a)$ the patient's serum reacts with a range of cell lines that contain intermediate filaments composed of vimentin, but not with cells whose intermediate filaments are composed of different protein subunits; $(b)$ in $\mathrm{PTK}_{2}$ epithelioid cells the serum reacts with the class of filaments that coils around the nucleus after colchicine treatment (vimentin) and not with the filaments that remain dispersed after colchicine (prekeratin); and (c) the component of reactive cells that combines with the serum is shown by immunoelectrophoresis to be a 58,000-mol wt protein antigen. A similar antibody that binds intermediate filaments of PTK $_{2}$ cells was encountered at lower titer in some sera from other patients with connective tissue diseases and in control sera. Previous routine antinuclear antibody assays using mouse liver or commercially prepared HEp-2 cells have failed to reveal anticytoskeletal an-

Dr. Senecal is a Fellow of the Canadian Arthritis Society. Dr. Oliver holds an American Cancer Society Faculty Research Award.

Received for publication 23 September 1981 and in revised form 7 December 1981. tibodies in patient sera, perhaps due to inadequate presentation or preservation of cytoplasmic antigens.

\section{INTRODUCTION}

The cytoskeleton of vertebrate cells consists of three principal elements: microtubules, which are 24-nm Diam hollow fibers composed primarily of tubulin, microfilaments that are actin-containing fibers $\sim 6 \mathrm{~nm}$ in Diam and intermediate filaments (INFIL), ${ }^{1}$ fibers of $\sim 10 \mathrm{~nm}$ Diam that consist of at least five biochemically and immunologically distinct types (1-6). INFIL composed primarily of vimentin (mol wt $\sim 58,000$ ) are most characteristic of mesenchymal cells; cytokeratins (a class of proteins of mol wt 42-65,000) are the major INFIL proteins of epidermal cells and are also found in some cell lines derived from nonkeratinizing epithelia; desmin (mol wt 50,000) is the predominant INFIL protein of muscle cells; and neurofilament proteins (a triplet of mol wt 210,000, 160,000, and 68,000) and glial fibrillary acidic protein (subunit mol wt 50,000) characterize the INFIL of neuronal and glial cells, respectively. Various accessory proteins, for example, synemin (mol wt 230,000) and a class of cation proteins called filaggrins (7) interact with INFIL. Individual cells may contain different amounts and more than one type of INFIL.

We report here the presence of a high titer antibody to INFIL in serum from a patient with a connective

\footnotetext{
${ }^{1}$ Abbreviations used in this paper: ANA, antinuclear antibodies; BSA, bovine serum albumin; INFIL, intermediate filaments; PBS, phosphate-buffered saline.
} 
tissue disease. The class of INFIL recognized by this antibody is inferred from analysis of the range of immunoreactive cells and of the characteristic pattern of filament distribution within individual cells. The identity of the primary antigen is confirmed by immunoelectrophoresis.

\section{METHODS}

Patient. M.S., a 43-yr-old white woman with a 20-yr history of Raynaud's phenomenon, developed calcinosis, esophageal motility disorder, sclerodactyly, and tèlangiectasis (CREST syndrome) in 1976. In December 1980, she was hospitalized with recent alopecia and mononeuritis multiplex, and a nonhemolytic anemia. A lupus erythematosus (LE) preparation was positive. The serum C3 was $62.4 \mathrm{mg} /$ $100 \mathrm{ml}$ (normal $>64 \mathrm{mg} / 100 \mathrm{ml}$ ). The native DNA binding was $68.4 \%$ (normal $<40 \%$, Farr assay) and the Crithidia Luciliae test for antibodies to DNA was positive in a titer of 1:640. Anti-smooth muscle antibodies were absent. Antinuclear antibodies (ANA) were detected with a titer of 1:512 using mouse liver and to a titer of 1:2,560 using HEp2 cells supplied by Antibodies Inc., Davis, Calif.

Cell lines. HEp-2, derived from a human laryngeal epidermoid carcinoma; PTK $_{2}$, derived from rat kangaroo kidney epithelium; CHO, from Chinese hamster ovary epithelium; and 3T3 mouse fibroblasts were from the American Type Culture Collection, Camden, N. J. (ATCC). B77 Rat 1 fibroblasts were generously provided by Dr. R. O. Hynes, Massachusetts Institute of Technology, and human primary skin fibroblasts were gifts of Drs. H. Malech, Department of Medicine, Yale Medical School. BN1010 rat neuronal cells were a gift of Dr. S. Pfeiffer, Department of Microbiology, University of Connecticut Health Center. Mouse primary enamel epithelium cultures were the generous gift of Dr. E. Kollar, Department of Oral Biology, University of Connecticut Health Center (8). Dr. Kollar also provided primary (2-4 d) cultures of embryonic mouse dermis containing colonies of keratinocytes surrounded by skin fibroblasts. Cells were grown on 13-mm glass coverslips in $35-\mathrm{mm}$ tissue culture dishes using RPMI medium with 10 or $20 \%$ fetal calf serum.

Antibodies. Antitubulin and antiactin antibodies were described elsewhere (9). Dr. R. O. Hynes kindly provided rabbit antirat fibroblast $58,000-\mathrm{mol}$ wt protein (vimentin) antibody (10). Fluorescein-conjugated second antibodies were from N. L. Cappel Laboratories, Downingtown, $\mathrm{Pa}$.

Indirect immunofluorescence labeling. Cell monolayers were permeabilized for $1 \mathrm{~min}$. at $37^{\circ} \mathrm{C}$ with $0.5 \%$ Triton $\mathrm{X}$ 100 in phosphate-buffered saline (PBS) and fixed in methanol at $-10^{\circ}$ for $5 \mathrm{~min}$. They were rinsed in PBS with $1 \%$ bovine serum albumin (PBS-BSA), incubated for $30 \mathrm{~min}$ at $37^{\circ} \mathrm{C}$ with various dilutions of patient sera or anticytoskeletal antibodies, rinsed again, and further incubated $(30 \mathrm{~min}$ at $37^{\circ} \mathrm{C}$ ) with appropriate fluorescein conjugated immunoglobulins. Cells were mounted in $50 \%$ glycerol and observed by epi-illumination in a Zeiss fluorescence microscope (Carl Zeiss, Inc., New York). The distribution of fluorescence was recorded by photography on Kodak Tri-X-Pan or high speed Ektachrome film (Eastman-Kodak, Co., Rochester, N. Y.).

Immunoelectrophoresis. Triton extracts of $\mathrm{PTK}_{2}$ or $\mathrm{CHO}$ cells (11) were solubilized with SDS and constituent proteins separated by polyacrylamide gel electrophoresis using Laemmli gels (12). The proteins were transferred onto nitrocellulose sheets by the electrophoretic procedure (electro- blot) of Towbin et al. (13) and reacted sequentially with M.S. serum (1:25 dilution in PBS-BSA; $1 \mathrm{~h})$, three changes of buffer (30 min each); and either fluorescein anti-human IgM $(1: 20 ; 1 \mathrm{~h})$ or anti-human $\operatorname{IgM}(1: 20,1 \mathrm{~h})$ and ${ }^{125} \mathrm{I}$ protein A $(1 \mathrm{~h})$. After extensive washing, fluorescent gels were observed under a Zeiss fluorescence microscope using a $2 \times$ objective. Protein A-conjugated gels were exposed to $x$-ray film for $5 \mathrm{~h}-3 \mathrm{~d}$. Fluorescence or autoradiographic patterns were compared with parallel Coomassie Blue-stained gels.

\section{RESULTS}

Observation and immunological characterization of an antibody to INFIL. HEp-2 cells provided in ANA assay kits by Antibodies, Inc. showed indistinct cytoplasmic fluorescence and striking nuclear and centromere fluorescence after incubation with M.S. serum (1:20) and fluorescein anti-human immunoglobulins (Fig. 1A). At dilutions of M.S. serum >1:160, cytoplasmic fluorescence was absent and the centromere pattern was prominant (Fig. 1B). In contrast, freshly grown HEp-2 and $\mathrm{PTK}_{2}$ cells treated with M.S. serum and fluorescein anti-human Igs revealed an intricate, wavy, three-dimensional filamentous network that showed an increased density around the nucleus and spread throughout the cytoplasm (Fig. 1C). These filaments formed a cage or basket around the chromosomes of mitotic cells. Mitotic spindles were unstained. Nuclear fluorescence was typically diffuse or peripheral.

The INFIL pattern observed in $\mathrm{PTK}_{2}$ cells labeled with rabbit anti-rat 58,000-mol wt (vimentin) antibody was closely similar to the cytoplasmic pattern due to M.S. serum. Entirely different patterns were obtained in $\mathrm{PTK}_{2}$ labeled with goat anti-bovine brain tubulin (where interphase cells contained microtubules focused upon centrioles and mitotic cells showed intensely fluorescent mitotic spindles) and with human anti-actin (where parallel microfilament bundles were labeled).

INFIL labeling of $\mathrm{PTK}_{2}$ cells with M.S. serum was readily observed to a serum dilution of $1: 800$. It required the presence of anti-human IgM: INFIL were not observed when specific fluorescein anti-IgG or anti-IgA were used as second antibody or when serum was treated with $1 \%$ mercaptoethanol to dissociate pentameric IgM. The same high titer IgM anti-INFIL antibody was present in four other M.S. sera collected between 1976-1981.

The range of immunoreactive cells. Table $I$ is a summary of the major INFIL proteins of a range of different cell types and the reactivity of M.S. serum toward these cells. Vimentin INFIL have been described in all the immunoreactive cell lines $(2,4,14-$ 16). In contrast, vimentin is not a major INFIL protein of any of the cells that did not react with M.S. serum 

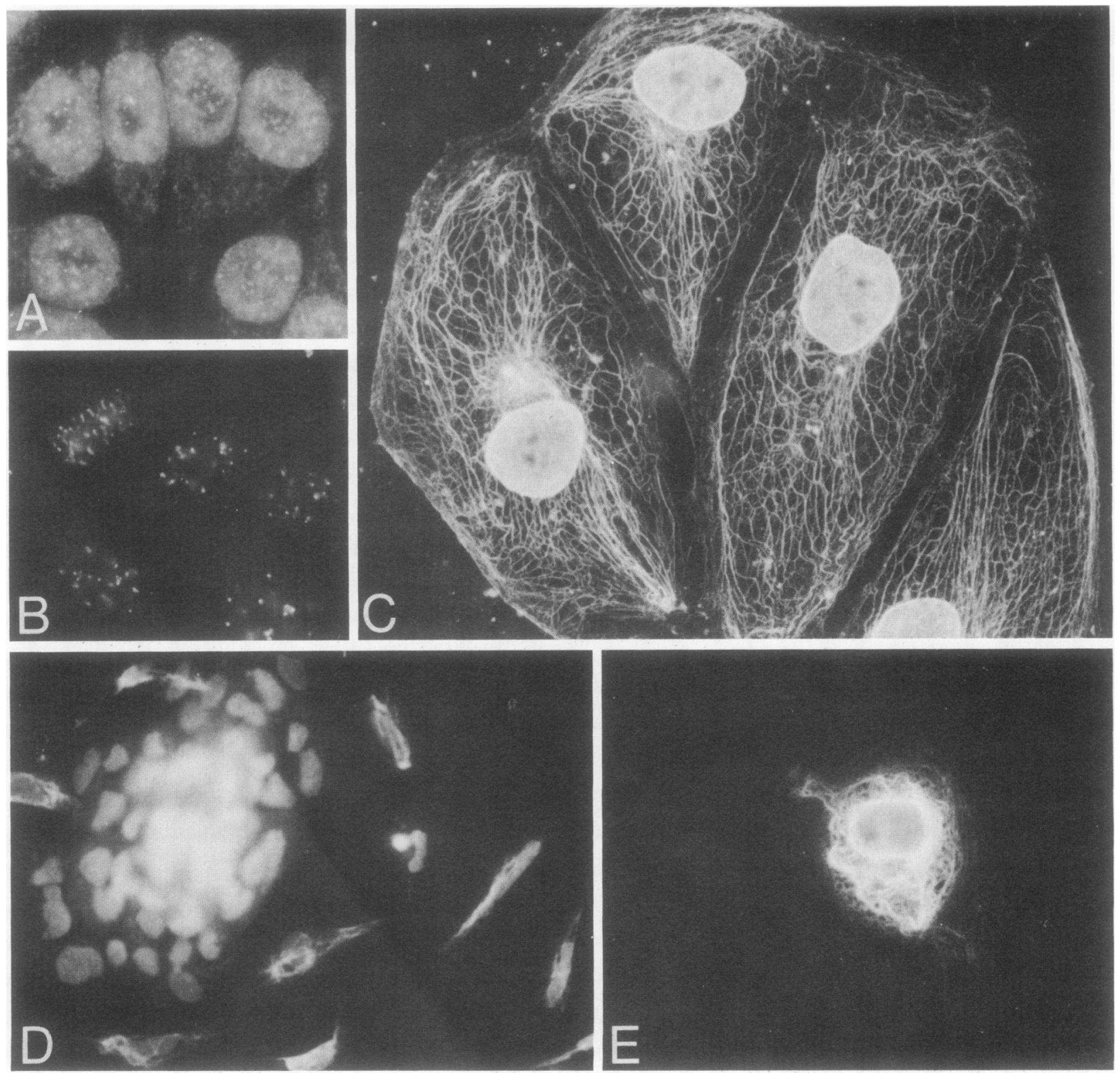

FIgURE 1 Identification of the anti-INFIL antibody by immunofluorescence microscopy. A, fluorescence pattern due to M.S. serum (1:20) and fluorescein anti-human immunoglobulins in commercially prepared HEp-2 cells, showing prominent nuclear labeling and indistinct centromere (kinetochore) and cytoplasmic fluorescence. B, fluorescence pattern due to M.S. serum (1:160) in commercial HEp-2, selected to emphasize the antibody to centomeres in a mitotic (metaphase) cell. C, freshly grown and fixed PTK $_{2}$ cells labeled with M.S. serum (1:50) and anti-human immunoglobulins showing intense staining of a meshwork of cytoplasmic filaments and diffuse nuclear fluorescence. D, fluorescence due to M.S. serum (1:50) staining of a mixed culture of primary mouse skin fibroblasts (single cells with cytoplasmic fluorescence) and primary mouse keratinocytes (epithelial clumps with immunoreactive nuclei and unreactive cytoplasm). E, the coiling of M.S. serum-labeled INFIL around the nucleus and their total absence from the cell margin in a PTK $\mathrm{P}_{2}$ cell treated with colchicine $(1 \mu \mathrm{M} ; 12 \mathrm{~h}) . \mathrm{M} \times 1250(\mathrm{D} \times 625)$.

$(2,3,6,8)$. In the case of primary mouse skin cultures (Fig. 1D) unreactive keratinocytes (reported to contain only prekeratin INFIL) were surrounded by reactive fibroblasts (primarily vimentin INFIL). All cells examined bound M.S. antibodies to nuclear antigens, indicating adequate antibody penetration. 
TABLE I

Reaction of M.S. Serum with the Intermediate Filaments of Various Cell Lines

\begin{tabular}{|c|c|c|c|c|}
\hline Class & Cells tested & Major INFIL protein & Ref. & $\begin{array}{l}\text { Reaction with } \\
\text { M.S. serum }\end{array}$ \\
\hline \multirow[t]{4}{*}{ Fibroblastic } & 3T3 & Vimentin & 14 & + \\
\hline & B77 Rat 1 & Vimentin & $-^{\circ}$ & + \\
\hline & Primary human skin & Vimentin & ${ }^{\bullet}$ & + \\
\hline & Primary mouse skin & Vimentin & 2 & + \\
\hline \multirow[t]{6}{*}{ Epithelioid } & $\mathrm{CHO}$ & Vimentin & 15 & + \\
\hline & $\mathrm{PTK}_{2}$ & Vimentin, prekeratin & 4,16 & + \\
\hline & HEp-2 & Vimentin, prekeratin & -1 & + \\
\hline & Primary mouse keratinocytes & Prekeratin & 2 & - \\
\hline & Primary mouse enamel & & & \\
\hline & epithelium & Prekeratin & 8 & - \\
\hline Smooth Muscle & Mouse stomach & Desmin & 3 & - \\
\hline Neuronal & BN1010 & Neurofilament protein & $6 \S$ & - \\
\hline
\end{tabular}

- Based on INFIL labeling with rabbit-anti $58,000-\mathrm{mol}$ wt (vimentin) antibody (this report).

$\downarrow$ INFIL are labeled with rabbit anti-58,000-mol wt (vimentin) antibody (this report). The presence of prekeratin INFIL in HEp-2 is assumed from the epidermal origin of this cell line.

$\$$ The presence of neurofilament protein in BN1010 is assumed by analogy with other neuronal cells.

Antibody adsorption. M.S. serum (0.5 $\mathrm{ml}$ of $1: 25$ dilution) was adsorbed at $4^{\circ} \mathrm{C}$ overnight against 0.1 $\mathrm{ml}$ of packed $\mathrm{CHO}$ cell extract. The $\mathrm{CHO}$-adsorbed serum was unreactive towards INFIL of $\mathrm{PTK}_{2}$ cells. Because CHO contain only vimentin INFIL (15), elimination of reactivity in $\mathrm{PTK}_{2}$ by $\mathrm{CHO}$ adsorbtion is consistent with a specific antivimentin antibody in M.S. serum.

Effects of colchicine on INFIL distribution. Weber and co-workers $(4,16)$ have shown that colchicine

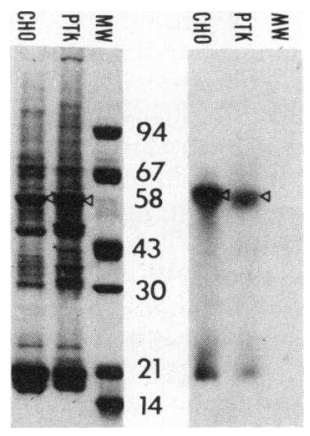

FIGURE 2 Identification of the anti-INFIL antibody by immunoelectrophoresis. Left panel, Coomassie Blue-stained gel patterns of $\mathbf{C H O}$ cell extract, $\mathrm{PTK}_{2}$ extract and molecular weight markers. The arrow indicates the position of the 58,000-mol wt (vimentin) band. Right panel, autoradiographic pattern of the electroblot of a parallel gel after reaction with MS serum and ${ }^{125} \mathrm{I}$-protein $A$. The $58,000-\mathrm{mol}$ wt protein is specifically labeled. treatment $(1 \mu \mathrm{M} ; 12 \mathrm{~h})$ causes the vimentin INFIL of $\mathrm{PTK}_{2}$ cells to coil around the nucleus, whereas the prekeratin INFIL remain dispersed in the cytoplasm. The filaments recognized by M.S. serum were coiled into a juxtanuclear mass after colchicine treatment (Fig. 1E).

Immunoelectrophoresis. SDS-gel electrophoretograms of $\mathrm{PTK}_{2}$ and $\mathrm{CHO}$ cells were examined for proteins that bound M.S. serum and could be visualized with fluorescein anti-IgM or anti-IgM ${ }^{125}$ I-protein $\mathrm{A}$. M.S. serum recognized a single protein in Triton extracts of both $\mathrm{PTK}_{2}$ and CHO cells. This band was coincident with vimentin, the major 58,000 -mol wt protein of $\mathrm{CHO}$ extracts and one of several major proteins in $\mathrm{PTK}_{2}$ extracts (Fig. 2).

Other sera. Antibodies to INFIL have been noted in sera from 6 of 12 normal individuals in titers of 1:50 or greater. Sera from 12 of 24 patients with connective tissue diseases revealed anti-INFIL in titers of 1:50 or greater.

\section{DISCUSSION}

Sporadic reports of anticytoskeletal antibodies in human sera have appeared in the literature over the past decade. For example, antibodies to smooth muscle, now known to bind actin and desmin, have been found in serum from patients with chronic active hepatitis (17) and cancer (18). Antimitotic spindle antibodies occur in occasional patients with connective tissue diseases (19) and antitubulin has been reported as a tran- 
sient serum component during infectious mononucleosis (20). IgG antibodies to neurofilaments occur in Creutzfeld-Jakob disease and Kuru (21). Most significantly, IgM anti-INFIL (probably antidesmin) antibodies may be present during acute viral illnesses (22); IgM anti-INFIL antibodies thought to be directed against keratin have been observed in infectious mononucleosis (23) and rheumatoid arthritis (24); and a possible anti-vimentin antibody has been inferred in rheumatoid arthritis (25).

We describe here a persistent high titer IgM antibody to INFIL in a patient with serologic and clinical features of both the CREST syndrome and systemic lupus erythematosus. We did not detect anti-INFIL reaction during previous routine ANA assay of M.S. or other sera using mouse liver sections or commercially prepared HEp-2 cells. Inappropriate fixation or storage of these ANA substrates may have obscured the existence of anticytoskeletal antibodies in patient sera.

The specific protein of the INFIL complex recognized by M.S. serum was determined by its reactivity to specific cell types, by the intracellular distribution of antigen, and by immunoelectrophoretic analyses. M.S. serum interacts with vimentin INFIL based on: (a) reaction with a range of epithelioid and fibroblastic cells that contain 58,000-mol wt (vimentin) INFIL but not with cells whose INFIL are composed primarily of prekeratin (primary epithelium), desmin (smooth muscle) or neurofilament protein (neuronal cells); (b) reaction in $\mathrm{PTK}_{2}$ cells of M.S. antibody with the class of INFIL (vimentin) that coils around the nucleus following colchicine treatment and not with the class that remains dispersed after colchicine (prekeratin); and (c) reaction of M.S. antibody with a 58,000-mol wt protein (vimentin) on SDS gels of both $\mathrm{PTK}_{2}$ and CHO cell extracts.

It remains to be determined if antibodies to INFIL proteins contribute to the loss of cell functions or other aspects of the pathogenesis of connective tissue disease. Whether or not such antibodies are of clinical importance, they are useful tools to probe the structure and function of the mammalian cytoskeleton.

\section{ACKNOWLEDGMENTS}

This work was supported in part by National Institutes of Health grant AM-16576, American Cancer Society grant BC179, and a Clinical Research Center grant from the Arthritis Foundation.

\section{REFERENCES}

1. Goldmann, R. D., A. Milsted, J. A. Schloss, J. M. Starger, and M. J. Yerna. 1979. Cytoplasmic fibers in mammalian cells: cytoskeletal and contractile elements. Annu. Rev. Physiol. 41: 703-722.

2. Franke, W. W., E. Schmid, D. Breitkreutz, M. Ludker, P. Boukamp, N. E. Fusenig, M. Osborn, and K. Weber. 1979. Simultaneous expression of two different types of intermediate sized filaments in mouse keratinocytes proliferating in vitro. Differentiation. 14: 35-50.

3. Lazarides, E. 1981. Intermediate filaments-chemical heterogeneity in differentiation. Cell. 23: 649-650.

4. Henderson, D., and K. Weber. 1981. Immunoelectron microscopical identification of the two types of intermediate filaments in established epithelial cells. Exp. Cell. Res. 132: 297-311.

5. Davison, P. F. 1981. Intermediate filaments: intracellular diversities and interspecies homologies. Int. Cell Biol. pp. 1980.

6. Bennet, G. S., S. J. Tapscott, F. A. Kleinbart, P. B. Antin, and H. Holzer. 1981. Different proteins associated with 10-nanometer filaments in cultured chick neurons and nonneuronal cells. Science (Wash., D. C.) 212: 567-659.

7. Steinert, P. M., J. S. Cantieri, D. C. Teller, J. D. Lonsdale-Eccles, and B. A. Dale. 1981. Characterization of a class of cationic proteins that specifically interact with intermediate filaments. Proc. Natl. Acad. Sci. U. S. A. 78: 4097-4101.

8. Kollar, E. J., and M. Kerley, 1980. Odontogenesis: interaction between isolated enamel organ epithelium and dental papilla cells. Int. J. Skel. Res. 6: 163-170.

9. Berlin, R. D., and J. M. Oliver. 1978. Analogous ultrastructure and surface properties during capping and phagocytosis in leukocytes. J. Cell Biol. 77: 789-804.

10. Hynes, R. O., and A. T. Destree. 1978. $10 \mathrm{~nm}$ filaments in normal and transformed cells. Cell. 13: 151-163.

11. Cabral, F., M. C. Willingham, and M. M. Gottesman. 1980. Ultrastructural localization to $10 \mathrm{~nm}$ filaments of an insoluble $58 \mathrm{~K}$ protein in cultured fibroblasts. $\mathrm{J}$. Histochem. Cytochem. 28: 653-662.

12. Laemmli, U. K. 1970. Cleavage of structural proteins during the assembly of the bead of bateriophage TH. Nature (Lond.). 227: 680-685.

13. Towbin, H., T. Staehelin, and J. Gordon. 1979. Electrophoretic transfer of proteins from polyacrylamide gels to nitrocellulose sheets: Procedure and some applications. Proc. Natl. Acad. Sci. U. S. A. 76: 4350-4354.

14. Franke, W. W., E. Schmid, M. Osborn, and K. Weber. 1978. Different intermediate-sized filaments distinguished by immunofluorescence microscopy. Proc. Natl. Acad. Sci. U. S. A. 75: 5034-5038.

15. Cabral, F., M. M. Gottesman, S. B. Zimmerman, and P. Steinert. 1981. Intermediate filaments from Chinese hamster ovary cells contain a single protein. J. Biol. Chem. 256: 1428-1431.

16. Aubin, J. E., M. Osborn, W. W. Franke, and K. Weber. 1980. Intermediate filaments of the vimentin-type and the cytokeratin-type are distributed differently during mitosis. Exp. Cell. Res. 129: 149-165.

17. Lidman, K., G. Biberfeld, A. Fagraeus, R. Norberg, R. Tostensson, and G. Gutter. 1976. Anti-actin specificity of human smooth muscle antibodies in chronic active hepatitis. Clin. Exp. Immunol. 24: 266-272.

18. Kurki, P., I. Virtanen, S. Stenman, and E. Linder. 1978. Characterization of human smooth muscle autoantibodies reacting with cytoplasmic intermediate filaments. Clin. Immunol. Immunopathol. 11: 379-387.

19. McCarty, G. A., D. W. Valencia, M. J. Fritzler, and 
F. A. Barada. 1981. A unique antinuclear antibody staining only the mitotic spindle apparatus. N. Engl. J. Med. 305: 703 .

20. Whitehouse, J. M. A., N. Ferguson, and G. A. Currie. Autoantibodies to micro-tubules in infectious mononucleosis. 1974. Clin. Exp. Immunol. 17: 227-235.

21. Sotelo, J., C. J. Gibbs, Jr., and D. C. Gajdusek. 1980. Autoantibodies against axonal neurofilaments in patients with Kuru and Creutzfeld-Jacob disease. Science (Wash., D. C.) 210: 190-193.

22. Toh, B. H., A Yildiz, J. Sotelo, O. Osung, E. J. Holborow, and F. Kanakondi. 1979. Viral infections and IgM au- toantibodies to cytoplasmic intermediate filaments. 1979. Clin. Exp. Immunol. 37: 76-82.

23. Bretherton, L., and B. H. Toh. 1981. IgM autoantibody to intermediate filaments in infectious mononucleosis. J. Clin. Lab. Immunol. 5: 7-10.

24. Scott, D. L., J. P. Delamere, L. J. Jones, and K. W. Walton. 1981. Significance of luminar antikeratin antibodies to rat oesophagus in rheumatoid arthritis. Ann. Rheum. Dis. 40: 267-271.

25. Osung, O. A., M. Chandler, and E. J. Holborow. 1980. Antibody against $10 \mathrm{~nm}$ filaments in rheumatoid arthritis. Ann. Rheum. Dis. 39: 599-600. 